\title{
Stainless-Steel Thin Film as Passive Radiative Cooling Materials
}

\author{
Mourad Benlattar1*, El Mostafa Oualim², M'hammed Mazroui', Azeddine Mouhsen33, \\ Mohmmed Harmouchi ${ }^{3}$ \\ ${ }^{1}$ Laboratoire de Physique de la Matière Condensée, Faculté des sciences Ben M'sik, Université Hassan II, \\ Casablanca, Maroc \\ ${ }^{2}$ High School of Technology of Berrechid, Hassan I University, Berrechid, Morocco \\ ${ }^{3}$ Faculty of Sciences and Techniques, Hassan 1er University, Settat, Morocco \\ Email: "m.benlattar@um5s.net.ma, "benlattar1975@gmail.com
}

Received 7 January 2016; accepted 19 August 2016; published 22 August 2016

Copyright (C) 2016 by authors and Scientific Research Publishing Inc.

This work is licensed under the Creative Commons Attribution International License (CC BY).

http://creativecommons.org/licenses/by/4.0/

c) (i) Open Access

\section{Abstract}

Spectrally selective glazing system attracts great attention for energy efficient radiator applications. The present work reports the possibility of a specific shield (Stainless steel/Borosilicate glass) to provide passive cooling for the purpose of reducing the use of classical active method. Radiative cooling devices require a convective shield that blocks all incoming solar radiation, but should selectively reemit radiation in the "atmospheric-window" region. In this study, borosilicate glass substrate coated with a stainless steel thin film was prepared by thermal evaporation and low pressure $\left(6.3 \times 10^{-3}\right.$ bar) DC plasma sputtering, in order to achieve the radiative cooling effect. The optical properties of the optimal thickness thin film were measured in the wavelength range of $0.3-20 \mu \mathrm{m}$ by an OL-750 double-beam spectroradiometer. The thin film has high visible band reflectance with high infrared band emissivity across the full $8-13 \mu \mathrm{m}$; which indicates that stainless steel thin film can be used as good radiative cooling material.

\section{Keywords}

Radiative Cooling, Reflectance, Stainless-Steel Thin Film, Optical Properties, Emissivity

\section{Introduction}

Radiator serves an important role in buildings to enhance high quality of life. In architecture, borosilicate glass is prestigious for its carrying positive images such as transparency, natural brightness, modernity, freshness and

${ }^{*}$ Corresponding author.

How to cite this paper: Benlattar, M., Oualim, E.M., Mazroui, M., Mouhsen, A. and Harmouchi, M. (2016) Stainless-Steel Thin Film as Passive Radiative Cooling Materials. Optics and Photonics Journal, 6, 193-202. 
indoor-outdoor interaction. Ordinary glass is not convenient for building envelopes in cold and temperate climatic conditions because their properties do not satisfy strict requirements for low energy consumption in buildings. Borosilicate glass tubes are used due to their low thermal expansion and superior environmental resistance. Most thermal energies are passing through a glazing system in modern buildings, and it is important to control them for energy efficient radiator applications. Architectural design can play a major role in achieving a broader market penetration of solar heating and cooling options. Low-energy technologies, such as solar active or passive cooling options, should be emphasized. However, integrating the solar heating and cooling systems into the building envelope is a necessity if the systems are to be economically feasible. Typically, it can be roof or facade integrations such as wall, balcony, awning or shade of the building. The integration is only possible if the design of the solar technology is included in the design of the building.

Radiative cooling has many others potential applications [1]-[3], including keeping food, seeds and water desalinization. The energy consumption related to cooling of buildings is steadily increasing as a consequence of the world-wide industrialization and increasing living standard. Solar heating systems have often been modified for radiative cooling applications, or systems were designed in order to serve both solar heating and radiative cooling [4] [5]. Passive radiative cooling is one among today's challenges in materials science research it occurs when a body gets cold by losing energy through radiative processes. The phenomenon of radiative cooling uses the fact that the thermal energy emitted by a clear sky in the "atmospheric window region" $(8-13 \mu \mathrm{m})$ [6] [7] is much less than the thermal energy emitted by a blackbody at ground air temperature in this wavelength range. For this reason, the surface on the earth facing the sky experiences an imbalance of outgoing and incoming thermal radiation and cools to below the ambient air temperature. While this concept can work well at night, assuming a relatively dry atmosphere, the solar energy absorbed during the day, which is normally much greater than that has radiated out, causes heating of the system. To prevent this, a shield is needed to cover the radiating surface in order to stop solar radiation during the day as well as possible to prevent convective mixing in the cooled space. A shield possibly changes this and promotes cooling or, at least, avoids heating. The use of stainless-steel as an optical thin-film material on borosilicate glass for production of elements for regulating thermal energy emittance, especially for highly reflecting mirrors of solar thermal devices, requires appropriate environmental protection. The reduction of radiation losses of a radiator depends on the low-emissivity coating on its optical and radiative properties. Stainless-steel low-emissivity coatings reduce absorptance of infrared radiation into a glass shield.

The use of optical materials improves the efficiency in passive cooling and energy efficient windows. There are two principal configurations of a shield that can be used for passive cooling application.

The first configuration is the use of infrared transparent shields in order to evacuate IR radiation via atmospheric window region. With an infrared transparent radiatif shield, it is possible for the radiator surface to cool to temperatures below ambient [8] [9].

In the second design, the cover is opaque to both solar light and the IR. If the upper side of the cover has a high solar reflectance and a high IR emissivity, most of the absorbed power from the sun will be emitted as thermal radiation towards the sky and the temperature of the cover will be close to that of the ambience [10] [11]. This paper deals only with the second design covers employing (Stainless steel/Borosilicate glass) system.

In this study, Stainless steel thin films coating on borosilicate glass substrate and their optical properties were discussed in order to assess the possibility of stainless steel thin film for radiative cooling system uses. Vacuum evaporation is generally used to deposit such films. In this work, we use the sputtering technique for stainless steel film preparation. This method appears promising for the design of radiative cooling shield, where specific properties are required [12].

\section{Stainless Steel Sputtering}

A series of multilayer films with different stainless steel layer thicknesses were prepared. The films prepared for this study consist of stainless steel $(45,115,150$ and $195 \mathrm{~nm})$ thick coating a float borosilicate glass sheet $(3 \mathrm{~mm})$. The borosilicate glass substrate was ultrasonically cleaned in acetone, rinsed in alcohol and then dried in flowing nitrogen gas. Metallization of the borosilicate glass substrate was performed by DC magnetron sputtering [12] with one target. A pressure of $6.3 \times 10^{-3}$ bar was maintained to produce the reactive plasma by applying $0.8 \mathrm{~A}$ with an advanced energy DC power supply. Film thicknesses were determined by measuring the step height between masked and unmasked regions on the substrate using a Dektak surface profiler. The deposition parameters are listed in Table 1. 
Table 1. Deposition parameters of thin films.

\begin{tabular}{cccc}
\hline Reactor pressure (bar) & Flow rate (sccm) & Electrical currents (A) & Discharge voltage (V) \\
\hline $6.3 \times 10^{-3}$ & 35 & 0.8 & $650-680$ \\
\hline
\end{tabular}

Sccm: standard cubic centimetre per minute.

\section{Experimental Instrument}

Spectral data (reflectance and transmittance) of stainless steel thin films are measured over the full $(0.3-20 \mu \mathrm{m})$ at room temperature using an OL-750 double-beam spectroradiometer, equipped with two different sources. A 150 Watt quartz-halogen lamp was used from $300 \mathrm{~nm}$ to 1 micron and an infrared, ceramic glower filament source, from 1 micron to 20 micron, which were kept up at a high stability. Errors due to source instabilities are minimized by means of a high stability controlled DC power supply. The modular approach of the spectro-radiometer OL-750 coupled with a powerful application software packages allows the user to ensure repeatability. The inaccuracy in the data of spectral specular reflectance and transmittance are estimated, from several measurements on different samples, to be less than $2 \%$ in the range from 3 to 16 micron. Above 16 microns, the inaccuracy may be larger.

The emitted light spectrum is scanned by a monochromator, which includes a rotating diffraction grating, in order to select a specific wavelength before interaction with the sample. The resolution was about $0.1 \mathrm{~nm}$ according to the grating adapted to each wavelength range. The light beam divergence is defined to be less than $1^{\circ}$ at the point of incidence on the sample. The monochromator sweeps the spectrally resolved light beam past a fixed detector. A silicon detector is used in the short wavelength range (0.2-1.1 micron) whereas a pyroelectric detector is used from 1 to 20 micron. The whole device was purged to eliminate water molecules. The normal transmittance is measured at a small incidence angle $\left(1^{\circ}\right)$ to reduce influence of multiple reflections, whereas the near-normal reflectance is measured at $20^{\circ}$ (Specular reflectance).

\section{Model for Radiative Cooling Effect}

In the model understudy used for the radiative cooling, the radiator is covered by a horizontal shield, which protects it from direct solar heating [10] [13].

The shield is assumed to steadily receive energy from the sun and the atmosphere. The shield absorbs some of the coming energy from the sun and the atmosphere, reflects back a part in the space and transmits the rest toward the absorber.

The absorber emits thermal radiation toward the shield which is partially reflected and absorbed by the absorber (radiator). The absorber emits hemispherical thermal radiation toward the window which is partially reflected and absorbed by the radiator. At the thermal equilibrium, the shield radiates its hemispherical thermal energy toward the space and absorber according to Lambert's law (Figure 1). The shield is characterized at each wavelength by two spectral transmittance coefficients $\left(T_{1}(\lambda), T_{2}(\lambda)\right)$ and by its two spectral reflectance coefficients $R_{1}(\lambda)$ and $R_{2}(\lambda)$ corresponding, respectively, to the waves traveling from the upper face (side 1) to the lower face (side 2 ) and from the (side 2 ) to the (side 1). The same for spectral absorptance coefficient, we have $A_{1}(\lambda)$ and $A_{2}(\lambda)$. These coefficients verify the following relation

$$
A_{i}(\lambda)+R_{i}(\lambda)+T_{i}(\lambda)=1, i=1,2
$$

In order to compare characteristic optical properties of the two faces of the sample, optical functions are defined, following the definition of Nilsson et al. [14]. The solar band reflectance $\left(R_{\text {sol }}\right)$ is estimated as the average spectral reflectance over the entire solar spectrum $(0.3<\lambda<2.5 \mu \mathrm{m})$, as given by

$$
R_{\text {sol }}=\int_{0.3}^{2.5} R(\lambda) W(\lambda) \mathrm{d} \lambda / \int_{0.3}^{2.5} W(\lambda) \mathrm{d} \lambda,
$$

where $W(\lambda)$ is the solar spectrum AM1.5[15] and $R(\lambda)$ is the spectral reflectance of the sample face.

Similarly, we calculated the solar band transmittance $\left(T_{\text {sol }}(\lambda)\right)$ and solar band absorptance $\left(A_{\text {sol }}(\lambda)\right)$ as given by the following equations

$$
T_{\text {sol }}=\int_{0.3}^{2.5} T(\lambda) W(\lambda) \mathrm{d} \lambda / \int_{0.3}^{2.5} W(\lambda) \mathrm{d} \lambda,
$$




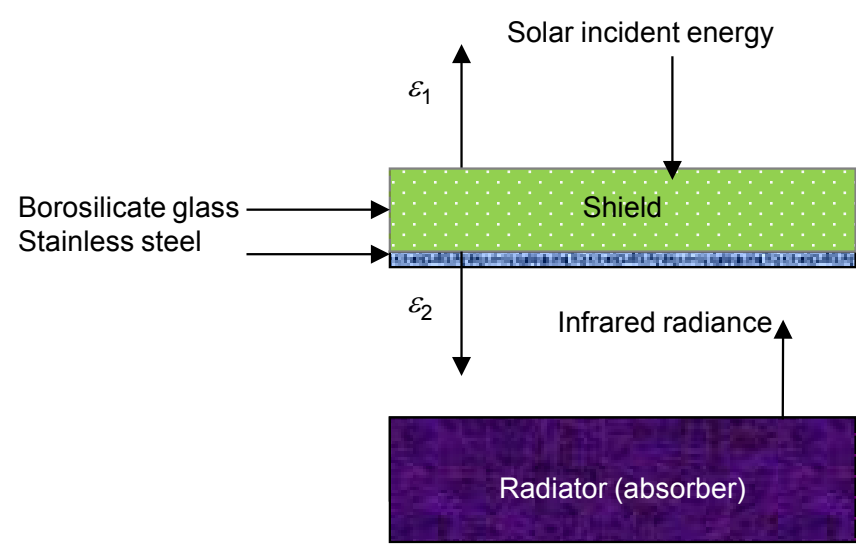

Figure 1. The schematic description of the model.

and

$$
A_{\text {Sol }}=1-\left(R_{\text {sol }}+T_{\text {Sol }}\right)
$$

Applying the same calculation method in the atmospheric window ( 8 - 13 microns) is a more complex issue, since the sky spectrum (atmospheric window range) is highly dependent on the humidity of the atmosphere.

The minimum parameters required to characterize the atmosphere specrtum for optical modeling and spectral measurements research are turbidity, water vapor and carbon dioxide [16] [17].

For simplicity, we will use the atmospheric spectral transmission for clear sky as reported for the AM1.5 by Berdhal and Fromberg [18], and in the same way, $T_{8-13 \mu \mathrm{m}}, R_{8-13 \mu \mathrm{m}}$ and $A_{8-13 \mu \mathrm{m}}$ are calculated in the atmospheric window range.

$$
\begin{aligned}
& R_{8-13 \mu \mathrm{m}}=\int_{8}^{13} R(\lambda) \zeta_{a}(\lambda) \mathrm{d} \lambda / \int_{8}^{13} \zeta_{a}(\lambda) \mathrm{d} \lambda, \\
& T_{8-13 \mu \mathrm{m}}=\int_{8}^{13} R(\lambda) \zeta_{a}(\lambda) \mathrm{d} \lambda / \int_{8}^{13} \zeta_{a}(\lambda) \mathrm{d} \lambda,
\end{aligned}
$$

where $\zeta_{a}(\lambda)$ is the atmospheric spectrum transmittance.

$$
A_{8-13 \mu \mathrm{m}}=1-\left(R_{8-13 \mu \mathrm{m}}+T_{8-13 \mu \mathrm{m}}\right)
$$

The IR band properties are calculated for a spectral distribution of blackbody at radiance of $300 \mathrm{~K}$.

The solar absorptance $\alpha_{s}$ of an opaque material on a stack of thin films is described using Equation (8) with spectral reflectance data [19]. The spectral region of $0.3-2.5 \mu \mathrm{m}$ was used because this region contains approximately $96 \%$ of the solar radiation intensity.

In that equation $R(\lambda)$ is the reflectance, $I_{s}(\lambda)$ is the spectral intensity of solar radiation, and $\lambda$ and $\theta$ respectively represent the wavelength in micrometers and the incident angle of solar radiation. A low reflectance in the spectral region of $0.3-2.5 \mu \mathrm{m}$ causes high $\alpha$.

$$
\alpha=\frac{\int_{0.3}^{2.5}\left(1-R\left(\lambda, \theta=20^{\circ}\right)\right) I_{S}(\lambda, T) \mathrm{d} \lambda}{\int_{0.3}^{2.5} I_{S}(\lambda, T) \mathrm{d} \lambda}
$$

The coating thermal emissivity $\varepsilon_{N}$ is calculated by integrating spectral reflectance in the spectral region of $2.5-20 \mu \mathrm{m}$, expressed as [19]

$$
\varepsilon_{N}=\frac{\int_{2.5}^{20}\left(1-R\left(\lambda, \theta=20^{\circ}\right)\right) I_{b}(\lambda, T) \mathrm{d} \lambda}{\int_{2.5}^{20} I_{b}(\lambda, T) \mathrm{d} \lambda}
$$


where $I_{s}(T, \lambda)$ is the spectral solar radiance (air mass of AM1.5 [20], and $I_{b}(T, \lambda)$ is the spectral blackbody radiative intensity.

\section{Results and Discussion}

At the fixed borosilicate glass thickness $(3 \mathrm{~mm}$ ), Figure 2 and Figure 3 present the measured optical reflectance spectra of the Stainless-steel/Borosilicate glass system with different thicknesses of Stainless Steel layer. Coatings are single-layer stainless-steel of 45, 115, 150 and $195 \mathrm{~nm}$ thicknesses.

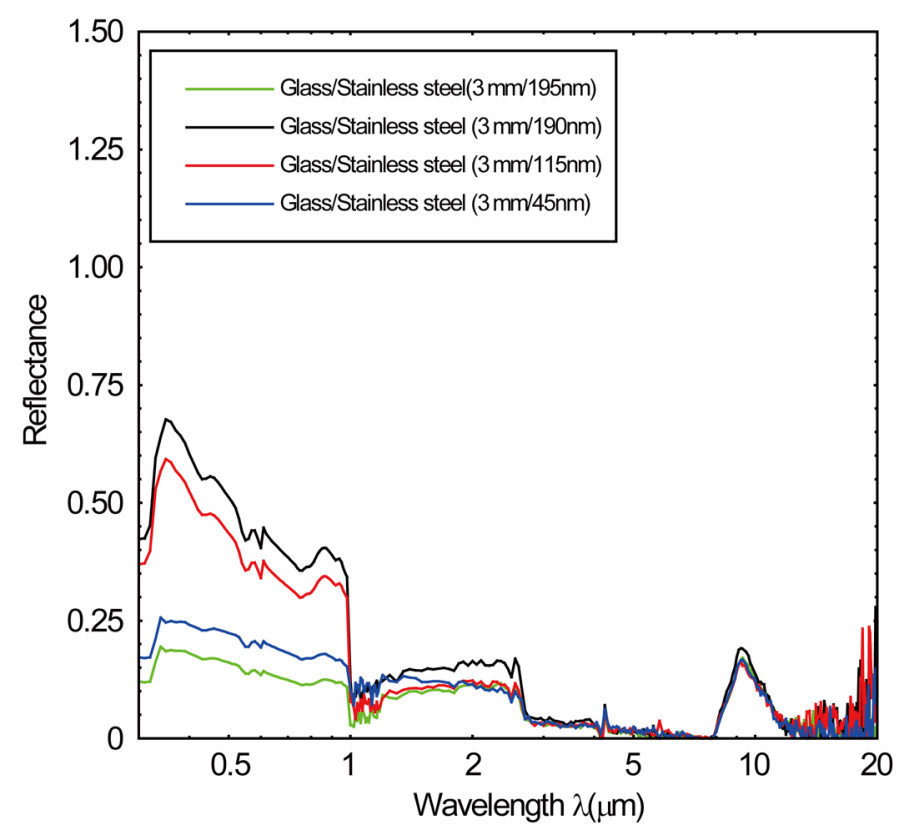

Figure 2. Measured reflectance spectra of thin film stainless-steel coatings of various thicknesses on, borosilicate glass substrate. Borosilicate glass is facing the incident beam (side 1).

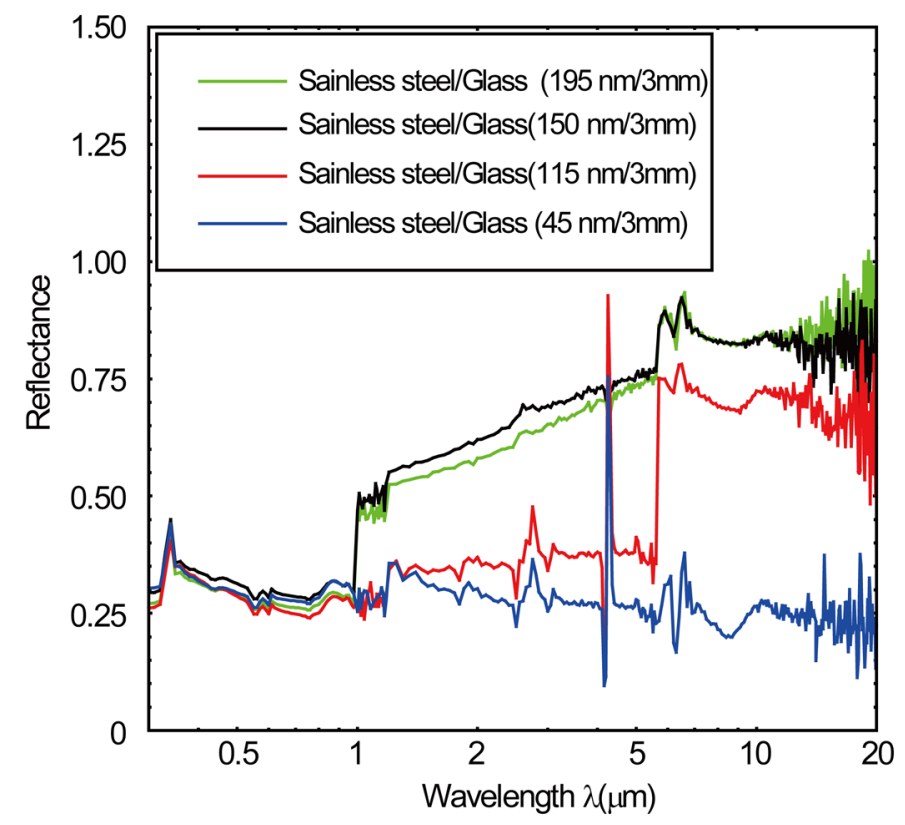

Figure 3. Measured reflectance spectra of thin film stainless-steel coatings of various thicknesses on borosilicate glass substrate. Stainless steel is facing the incident beam (side 2). 
As the system is not symmetric, measurements are carried out for the two different situations: 1) borosilicate glass facing the incident beam (side 1) and 2) metal coating facing the incident beam (side 2). Corresponding results are shown in Figure 2 and Figure 3, respectively.

The optical properties such as $\alpha_{s}$ and $\varepsilon_{N}$ of the coatings (Stainless-steel/Borosilicate glass) above study, evaluated at $300 \mathrm{~K}$, are listed in Table 2.

Figure 3 presents the optical reflectance spectra of the stainless-steel/borosilicate-glass system with different S.S. layer thicknesses for fixed thickness of borosilicate glass layer $(3 \mathrm{~mm})$. It is seen that as the thickness of S.S. layer increases, the reflectance increases but it decreases when the thickness of S.S. layer is about $150 \mathrm{~nm}$ and there is a shift to longer wavelength regions. It is observed that when the stainless steel thickness is or nearly equal to $150 \mathrm{~nm}$ thickness, the emissivity of stainless steel reaches a minimum value (Figure 4). The absorbed energy is preferentially reemitted toward the sky due to the high emissivity of borosilicate glass $(70 \%$ at $300 \mathrm{~K})$ compared to that of stainless-steel (18\%) [21].

If borosilicate glass is facing the sky, these configurations indicate that the top layer prevents the transmittance of the greatest part of radiation coming from the sky, and allows the bottom layer to evacuate most of the thermal radiation emitted by an underlying material, a black radiator in the present case. As a consequence, the blackbody covered by the present shield will support radiative cooling.

Figure 4 shows the thermal emissivity and solar absorptance of thin film stainless-steel coatings of various thicknesses on borosilicate glass substrate. The solar absorptance and thermal emissivity of film coated sample is calculated according to Equation (8) and Equation (9).

Table 2. Optical properties of the selective coatings.

\begin{tabular}{ccc}
\hline Thicknesses $(\mathrm{nm})$ & $\alpha_{s}($ side 1$)$ & $\mathcal{E}_{N}$ (side 2) \\
\hline 45 & 0.87 & 0.70 \\
115 & 0.75 & 0.52 \\
150 & 0.70 & 0.18 \\
195 & 0.90 & 0.21 \\
\hline
\end{tabular}

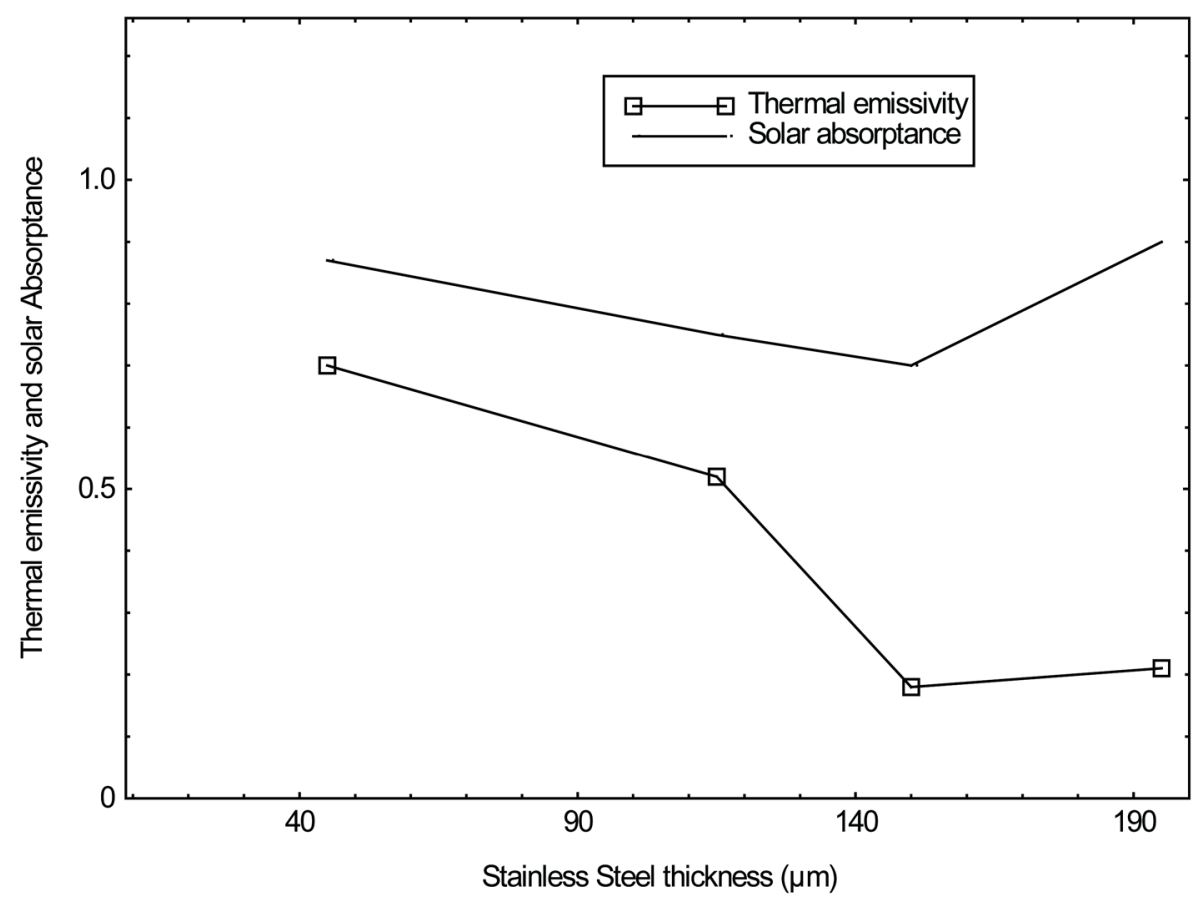

Figure 4. Calculated thermal emissivity and solar absorptance of borosilicate glass coated with signal-layer stainless-steel coating of various thickness. 
The spectral transmittance and reflectance of the optimal thickness of stainless steel thin film $(150 \mathrm{~nm})$ deposited on borosilicate glass substrate $(3 \mathrm{~mm}$ ) (side 2) are shown in Figure 5. From spectral reflectance, we can see the position of the critical point structure at $0.41 \mathrm{eV}(0.32 \mu \mathrm{m})$ [22]. For metals, the onset of this interband absorption is associated with transitions from Fermi surface to the next empty band or with transitions from a lower lying filled band to the Fermi surface. Interband absorption can be identified with the structure in the real and imaginary parts of the dielectric constant [23]. There is a high peak of reflectance around 4 micron in Figure 3, which seems to be due to abnormal skin-effect [10]. The stainless-steel film on a borosilicate glass substrate was used as spectrally selective filter that reflects most of the visible spectrum and absorbs infrared radiation (due to the properties of the metal layer). The highly reflective metal film, that otherwise transmits very little energy in the infrared region, was absorptive coatings so as to enhance the energy emitted in infrared window $(8-13 \mu \mathrm{m})$.

Figure 6 shows the spectral transmittance and reflectance of borosilicate glass substrate (side 1). It can be observed that the reflectance of the borosilicate glass (side 1) is higher in solar region and lower in the (1-20 $\mu \mathrm{m})$ except for the peak situated at $9 \mu \mathrm{m}$ corresponding to the O-Si-O bonding [24]. Most of the measurements for radiative cooling materials were made using a borosilicate glass substrate, but in some cases Si substrate was required [25]. Single-layer coating of $\mathrm{SiO}_{2}$ is the simplest and most promising coating for enhancing emissivity [26]. Borosilicate glass thin substrate is one of practical substrates for use as radiation shield. It was selected as the substrate material due to its availability and constant optical properties, which were difficult to obtain for the homemade samples. Therefore, borosilicate glass has high-emissivity behavior because due to low reflectance and to low transmittance results in a high absorptance in the IR window.

Optical measurements of the optimal thickness $(150 \mathrm{~nm} / 3 \mathrm{~mm})$ were carried out using two different configurations: in one, the side 1 and the side 2 (Figure 5 and Figure 6 respectively). Table 3 gives the above radiative properties for the shield reported in this work.

As expected, due to the presence of the thick metallic coating, the transmittance $T$ is found to be negligible in the whole wavelength range, both for the case of glass facing light and for the case of metal.

In the case of borosilicate glass facing the incident beam, the solar band reflectance over most of the solar region is rather high $\left(\mathrm{R}_{\mathrm{sol}}=0.24\right)$ and increases to $(0.52)$ in the visible region. As can be seen from Figure 6, the solar transmittance is reasonably very low in $\left(\mathrm{T}_{\mathrm{sol}}=0.07\right)$ and falls to a null value in the visible region. The window IR band transmittance is very low $\left(\mathrm{T}_{8-13 \mu \mathrm{m}}=0.03\right)$, but the IR band reflectance of the radiative object is very high 0.79 for the $8-13 \mu \mathrm{m}$ band, that is, the IR band emittance reaches $18 \%$.

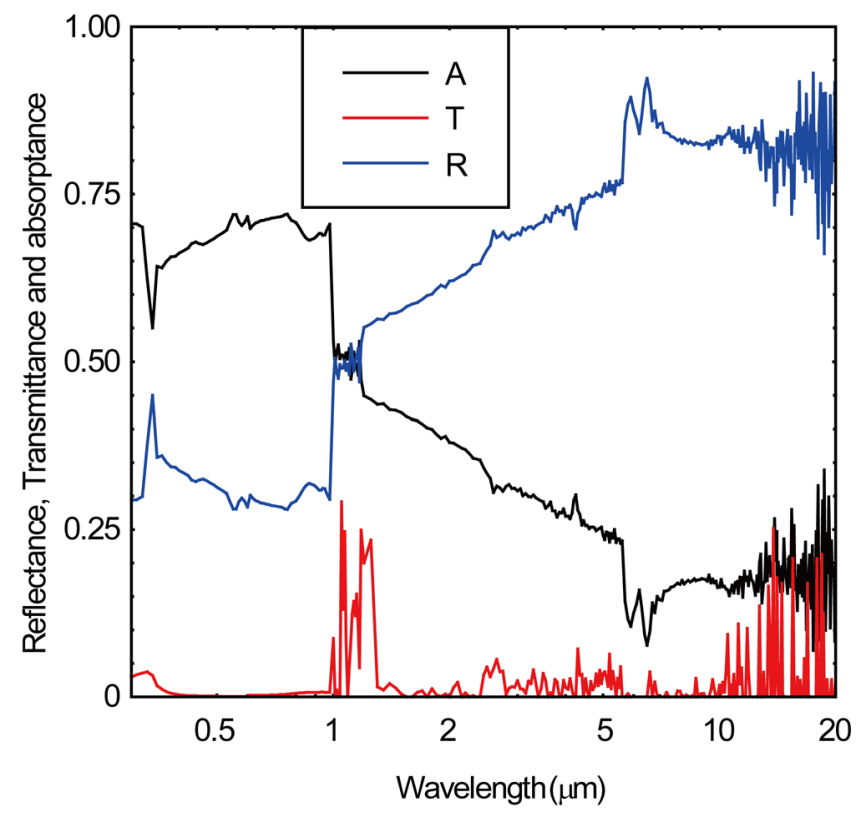

Figure 5. Reflectance $R(\lambda), T(\lambda)$ transmittance and absorptance $A(\lambda)$ for a 150 $\mathrm{nm}$-thick stainless steel film coated borosilicate glass $(3 \mathrm{~mm})$. Stainless steel is facing the incident beam. 
The concept of this approach is to combine high solar reflectance or scattering from the upper side of the shield and to high reemission in the "atmospheric-window" from the upper side of the shield. Such radiative properties values are suitable for passive cooling use [10] [27] [28].

In the second case, the incident beam, the reflectance is low $(0.27)$ between 0.3 and $1 \mu \mathrm{m}$, then it increases to reach the maximum (0.61) around $2 \mu \mathrm{m}$. The solar band transmittance is reasonably very low in $\left(\mathrm{T}_{\text {sol }}=0.04\right)$ and falls to a null value in the visible region. The window IR band absorptance is very high $\left(\mathrm{A}_{8-13}=0.88\right)$, but the IR band reflectance of the radiative object is very low 0.1 for the $8-13 \mu \mathrm{m}$ band, that is, the IR band emittance reaches $87 \%$.

The treated window is opaque to most of the visible radiation received from the sun. It has also an opaque behavior of the thermal radiation emitted by the absorber. It's checked that the emission of the treated side is very weak compared to that of the untreated side.

A consideration of the two geometries leads to an expected difference in the spectral specular reflectance. However, the side 2 facing blackbody appear to possess the best properties for use as a shield radiative cooling devices. In the conditions of a normal incidence $(\mathrm{T}=300 \mathrm{~K})$, the temperature of the black absorber, in the absence of the shield, is estimated at $364 \mathrm{~K}$. Using the measured radiative properties (Table 3), the computed temperature of the black absorber when it is covered by the shield is $288 \mathrm{~K}$ [29] [30]. The net radiative cooling power of a radiator $\left(\mathrm{P}_{\text {net }}\right)$ is the difference between the power radiated by the radiator at its operating temperature minus the power absorbed by the radiator from the sky [31] [32]. The cooling power $\left(\mathrm{P}_{\text {net }}\right)$ of the shield's surface is about $59 \mathrm{~W} / \mathrm{m}^{2}$. The maximal cooling power of a body at ambient temperature with high infrared emittance is in the range of $100 \mathrm{~W} / \mathrm{m}^{2}$ for clear night sky and low air humidity [7] [33] [34].

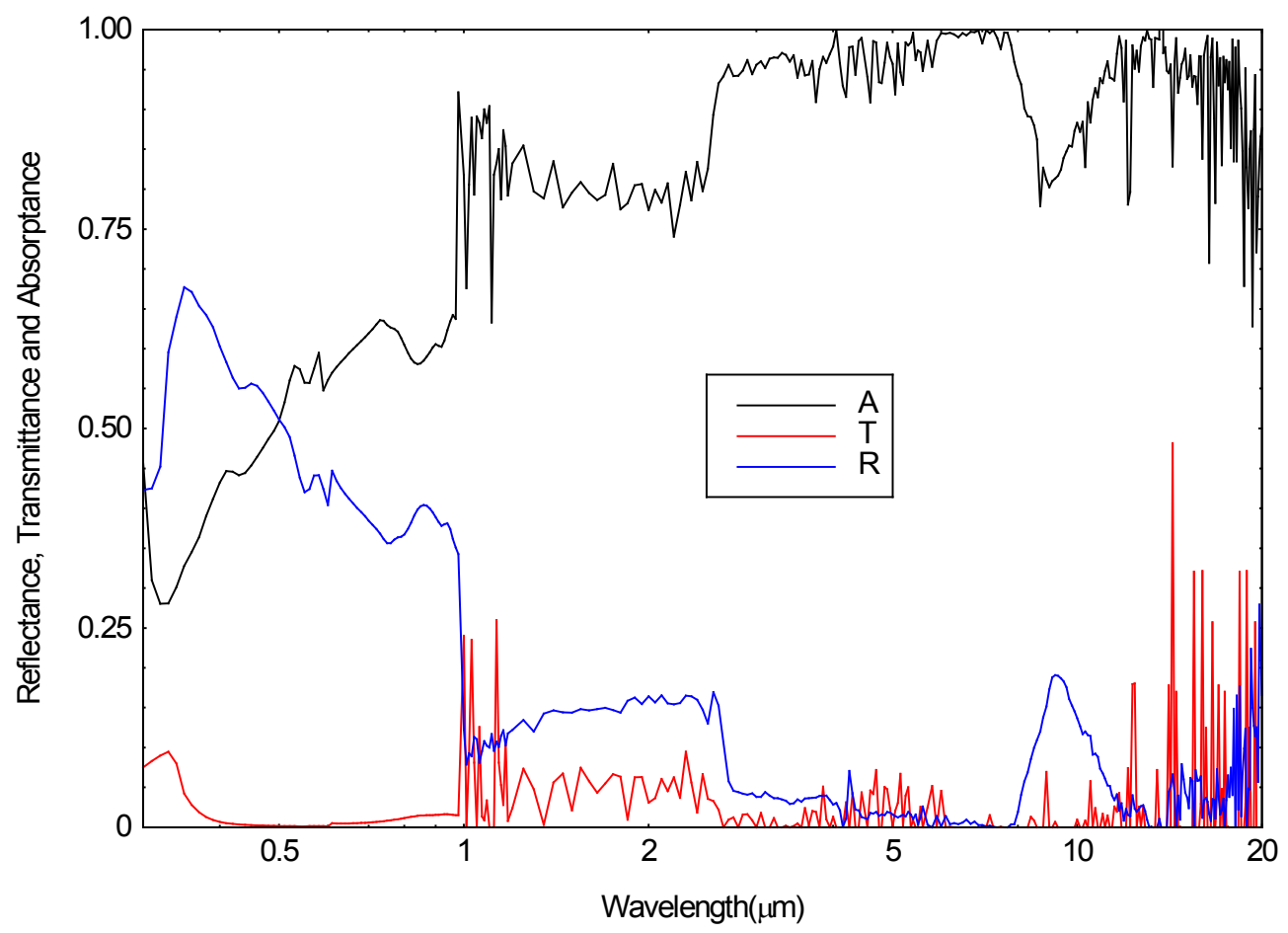

Figure 6. Reflectance $R(\lambda)$, transmittance $T(\lambda)$ and absorptance $A(\lambda)$ for a $150 \mathrm{~nm}$-thick stainless steel film coated borosilicate glass $(3 \mathrm{~mm})$. Borosilicate glass is facing the incident beam.

Table 3. Values of the optical functions, $R_{8-13}, T_{8-13}, A_{8-13}, R_{s o l}, T_{s o l}$ and $A_{s o l}$ of shield faces for application in radiative cooling devices.

\begin{tabular}{ccccccc}
\hline Sample & $\mathrm{R}_{\text {sol }}$ & $\mathrm{T}_{\text {sol }}$ & $\mathrm{A}_{\text {sol }}$ & $\mathrm{T}_{8-13 \mu \mathrm{m}}$ & $\mathrm{A}_{8-13 \mu \mathrm{m}}$ & $\mathrm{R}_{8-13 \mu \mathrm{m}}$ \\
\hline Side 1 & 0.24 & 0.07 & 0.69 & 0.02 & 0.88 & 0.1 \\
Side 2 & 0.39 & 0.04 & 0.57 & 0.03 & 0.18 & 0.97 \\
\hline
\end{tabular}




\section{Conclusion}

In summary, metallization of the borosilicate glass substrate was performed by DC magnetron sputtering. The optical properties of the film were measured in the Vis/near IR (solar) and mid-IR (atmospheric-window) regions both for the coated and for the uncoated faces. Radiative cooling properties were determined for a blackbody radiator shielded by a borosilicate glass cover coated with a stainless steel film. If the metallic coating is facing the radiator, this system was shown to possess suitable optical properties for use as a shield. Moreover, because of its high emissivity in the atmospheric transparency window, the stainless steel coating thin film could be used for radiative cooling.

\section{References}

[1] Martin, M. (1989) Radiative Cooling. In: Cook, J., Ed., Passive Cooling, MIT Press, Cambridge, MA, 138-196.

[2] Gransqvist, C.G. and Eriksson, T.S. (1991) Materials for Solar Energy Conversion Systems. Pergamon Press, Oxford.

[3] Agrawal, P.C. (1992) Review of Passive Systems and Passive Strategies for Natural Heating and Cooling of Buildings in Libya. International Journal of Energy Research, 16, 101-117. http://dx.doi.org/10.1002/er.4440160203

[4] Matsuta, M., Terada, S. and Ito, H. (1987) Solar Heating and Radiative Cooling Using a Solar Collector-Sky Radiator with a Spectrally Selective Surface. Solar Energy, 39, 183-186. http://dx.doi.org/10.1016/S0038-092X(87)80026-9

[5] Granqvist, C.G. (1990) Window Coatings for the Future. Thin Solid Films, 730, 193-194. http://dx.doi.org/10.1016/0040-6090(90)90225-3

[6] Dobson, K.D., Hodesa, G. and Mastaib, Y. (2003) Thin Semiconductor Films for Radiative Cooling Applications. Solar Energy Materials \& Solar Cells, 80, 283-296. http://dx.doi.org/10.1016/j.solmat.2003.06.007

[7] Rephaeli, E., Raman, A. and Fan, S. (2013) Ultrabroadband Photonic Structures to Achieve High-Performance Daytime Radiative Cooling. Nano Letters, 13, 1457-1461.

[8] Benlattar, M., et al. (2005) Radiative Properties of Cadmium Telluride Thin Film as Radiative Cooling Materials. $O p$ tics Communications, 265, 10-15. http://dx.doi.org/10.1016/j.optcom.2005.06.033

[9] Benlattar, M., et al. (2006) Thin Cadmium Sulphide Film for Radiative Cooling Application. Optics Communications, 267, 65-68. http://dx.doi.org/10.1016/j.optcom.2006.06.050

[10] Benlattar, M., Oualim, E.M., Harmouchi, M., Chebihi, A. and Belafhal, A. (2004) Mesure et Optimisation des Propriétés Optiques du Système $\mathrm{Ag} / \mathrm{SiO}_{2}$ pour la Réalisation de L'effet de Serre Inverse. Physical and Chemical News, 16, 26.

[11] Benlattar, M. and Oualim, E.M. (2013) Radiative Properties of Copper Thin Film as Radiative Cooling Materials. Journal of Science and Arts, 4, 391-395.

[12] Maissel, L.I. and Glang, R. (1983) Handbook of Thin Film Technology. McGraw-Hill, New York.

[13] Oualim, E.M., Harmouchi, M., Chebihi, A., Vigneron, J.P. and Lambin, P. (2001) Etudes théoriques et expérimentales de la sélectivité spectrale d'un film d'étain déposé sur le verre. Siceo, 119.

[14] Nilsson, T.M.J., Niklasson, G.A. and Granqvist, C.G. (1992) A Solar Reflecting Material for Radiative Cooling Applications: ZnS Pigmented Polyethylene. Solar Energy Materials and Solar Cells, 28, 175-193. http://dx.doi.org/10.1016/0927-0248(92)90010-M

[15] Walker, K.D., Saunders, R.D., Parr, J.J. and Hsia, J. (1990) The 1990 NIST Scales of Thermal Radiometry. Journal of Research of the National Institute of Standards and Technology, 95, 621-629. http://dx.doi.org/10.6028/jres.095.050

[16] Weiman, W.V.L. (1978) Report of 2nd WMO Expert Meeting on Turbidity Measurements. Boulder, Colorado.

[17] Berdahl, P. and Martin, M. (1978) The Resource for Radiative Cooling. Proceeding of 3rd National Passive Solar Conference, 2, 684-686.

[18] Berdahl, P. and Fromberg, R. (1982) The Thermal Radiance of Clear Skies. Solar Energy, 29, 299-314. http://dx.doi.org/10.1016/0038-092X(82)90245-6

[19] Shimazaki, K., Ohnishi, A. and Nagasaka, Y. (2003) Computational Design of Solar Reflection and Far-Infrared Transmission Films for a Variable Emittance Device. Optical Materials, 42, 1360-1366. http://dx.doi.org/10.1364/ao.42.001360

[20] http://rredc.nrel.gov/solar/spectra/am1.5

[21] Modest, M.F. (1993) Radiative Heat Transfer. McGraw-Hill, New York.

[22] Van Hove, L. (1953) The Occurrence of Singularities in the Elastic Frequency Distribution of a Crystal. Physical Re- 
view, 89, 1189-1193. http://dx.doi.org/10.1103/PhysRev.89.1189

[23] Ehrenreich, H. and Philipp, H.R. (1966) Optical Properties of Ag and Cu. Physical Review, 128, 1622-1629. http://dx.doi.org/10.1103/PhysRev.128.1622

[24] Miller, M. (1968) Infrared Absorption of Glassy Silicon Dioxide. Czechoslovak Journal of Physics B, 18, $354-362$. http://dx.doi.org/10.1007/BF01689836

[25] Martin-Palama, R.J., Vazquez, L., Martinez-Duart, J.M. and Malats-Riera, M. (1998) Silver-Based Low-Emissivity Coatings for Architectural Windows: Optical and Structural Properties. Solar Energy Materials and Solar Cells, 53, 55-66. http://dx.doi.org/10.1016/S0927-0248(98)00007-5

[26] Shimazaki, K., Imaizumi, M. and Kibe, K. (2008) $\mathrm{SiO}_{2}$ and $\mathrm{Al}_{2} \mathrm{O}_{3} / \mathrm{SiO}_{2}$ Coatings for Increasing Emissivity of $\mathrm{Cu}(\mathrm{In}$, $\mathrm{Ga}_{\mathrm{Se}}$ Thin-Film Solar Cells for Space Applications. Thin Solid Films, 516, 2218-2224. http://dx.doi.org/10.1016/j.tsf.2007.07.159

[27] Mouhib, T., et al. (2009) Stainless Steel/Tin/Glass Coating as Spectrally Selective Material for Passive Radiative Cooling Applications. Optical Materials, 31, 673-677. http://dx.doi.org/10.1016/j.optmat.2008.07.010

[28] Granqvist, C.G. (1981) Radiative Heating and Cooling with Spectrally Selective Surfaces. Applied Optics, 20, 26062615. http://dx.doi.org/10.1364/AO.20.002606

[29] Oualim, E.M. and Harmouchi, M. (2002) Réalisation Du Refroidissement Radiatif Par Une Lame De Verre Traitée Par l'Aluminium. Physical and Chemical News, 6, 23.

[30] Deureux, A., Vigneron, J.P., Lambin, P. and Lucas, A.A. (1987) Polariton Structure and Spectral Reflectance of Multilayered Semiconducting Materials. Physica Scripta, 35, 338-342. http://dx.doi.org/10.1088/0031-8949/35/3/020

[31] Eriksonn, T.S. and Granquist, C.G. (1982) Radiative Cooling Computed for Mode Atmospheres. Applied Optics, 21, 4381-4388. http://dx.doi.org/10.1364/AO.21.004381

[32] Goforth, M.A., Gilcrest, G.W. and Sirianni, J.D. (2002) Cloud Effects on Thermal Downwelling Sky Radiance. Proceedings of the SPIE, 4710, 203-213. http://dx.doi.org/10.1117/12.459570

[33] Argiriou, A., Santamouris, M., Balaras, C. and Jeter, S. (1993) Potential of Radiative Cooling in Southern Europe. Solar Energy, 13, 189-203.

[34] Mihalakakou, G., Ferrante, A. and Lewis, J.O. (1998) The Potential of a Metallic Nocturnal Radiator. Energy and Buildings, 28, 251-256. http://dx.doi.org/10.1016/S0378-7788(98)00006-1

\section{Submit or recommend next manuscript to SCIRP and we will provide best service for you:}

Accepting pre-submission inquiries through Email, Facebook, LinkedIn, Twitter, etc.

A wide selection of journals (inclusive of 9 subjects, more than 200 journals)

Providing 24-hour high-quality service

User-friendly online submission system

Fair and swift peer-review system

Efficient typesetting and proofreading procedure

Display of the result of downloads and visits, as well as the number of cited articles

Maximum dissemination of your research work

Submit your manuscript at: http://papersubmission.scirp.org/ 